\title{
Using mixed effects logistic regression models for complex survey data on malaria rapid diagnostic test results
}

\author{
Chigozie Louisa J. Ugwu ${ }^{* \dagger}$ and Temesgen T. Zewotir ${ }^{\dagger}$
}

\begin{abstract}
Background: The effect of malaria in Nigeria is still worrisome and has remained a leading public health issue in the country. In 2016, Nigeria was the highest malaria burden country among the 15 countries in sub-Saharan Africa that accounted for the $80 \%$ global malaria cases. The purpose of this study is to utilize appropriate statistical models in identifying socio-economic, demographic and geographic risk factors that have influenced malaria transmission in Nigeria, based on malaria rapid diagnostic test survey results. This study contributes towards re-designing intervention strategies to achieve the target of meeting the Sustainable Development Goals 2030 Agenda for total malaria elimination.
\end{abstract}

Methods: This study adopted the generalized linear mixed models approach which accounts for the complexity of the sample survey design associated with the data. The 2015 Nigeria malaria indicator survey data of children between 6 and 59 months are used in the study.

Results: From the findings of this study, the cluster effect is significant $(P<0.0001)$ which has suggested evidence of heterogeneity among the clusters. It was found that the vulnerability of a child to malaria infection increases as the child advances in age. Other major significant factors were; the presence of anaemia in a child, an area where a child resides (urban or rural), the level of the mother's education, poverty level, number of household members, sanitation, age of head of household, availability of electricity and the type of material for roofing. Moreover, children from Northern and South-West regions were also found to be at higher risk of malaria disease and re-infection.

Conclusion: Improvement of socio-economic development and quality of life is paramount to achieving malaria free Nigeria. There is a strong link of malaria risk with poverty, under-development and the mother's educational level.

Keywords: Generalized Chi-square statistic, Interaction effect, Link function, Odd ratios, Random effects, Sustainable Development Goals (SDGs)

\section{Background}

Almost half of the world's population has been at the risk of malaria, but in terms of mortality and morbidity attributed to the disease, the African children aged under 5 years have been mostly affected. According to the World Health Organization (WHO), year 2016 alone recorded 216 million cases of malaria infection and 445,000

\footnotetext{
*Correspondence: 217075063@stu.ukzn.ac.za

${ }^{\dagger}$ Chigozie Louisa J. Ugwu and Temesgen T. Zewotir contributed equally to this work

School of Mathematics, Statistics and Computer Science, University of KwaZulu-Natal, Westville Campus, Durban, South Africa
}

mortality cases worldwide, of which $91 \%$ occurred in African countries [1].

Of the fifteen countries in sub-Saharan Africa that accounted for $91 \%$ of the global malaria cases, Nigeria bears the major burden of about $40 \%$ which included $25 \%$ infant mortality, close to $31 \%$ under-five mortality and nearly $11 \%$ maternal mortality in annual bases [2]. Similarly, there are more than 100 million clinically diagnosed malaria cases, of which approximately 300,000 malaria associated childhood deaths occur yearly in Nigeria [3]. The effect of malaria disease in Nigeria is worrisome and has remained a leading public health issue in the country,

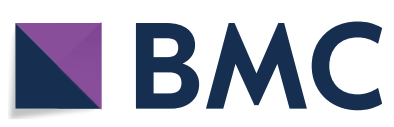

(c) The Author(s) 2018. This article is distributed under the terms of the Creative Commons Attribution 4.0 International License (http://creativecommons.org/licenses/by/4.0/), which permits unrestricted use, distribution, and reproduction in any medium, provided you give appropriate credit to the original author(s) and the source, provide a link to the Creative Commons license, and indicate if changes were made. The Creative Commons Public Domain Dedication waiver (http://creativecommons.org/ publicdomain/zero/1.0/) applies to the data made available in this article, unless otherwise stated. 
hence, a major cause of about $60 \%$ unscheduled hospital visits and more than $30 \%$ hospitalization of children and pregnant women in Nigeria [4]. Malaria parasitaemia is mainly observed during the first pregnancy, but decreases afterwards; pregnancy in turn reduces the inhabitance of normal immune response due to the infection and as such, may cause severe cases among them [5]. Malaria infection of the mother increases the risk of abortion, stillbirth and also the odd of congenital malaria transmission to newborns which will eventually reduce the infant's survival chances.

In Nigeria, malaria is endemic and has contributed to the huge economic loss to the nation due to its negative impact in the capacity of a debilitating work force and draining national resource due to the disease control and treatment [6]. Moreover, malaria disease affects mostly agricultural regions, the infection weakens its victim's strength by making the individual succumb to other infectious diseases and as such, affects country's agricultural efficiency [7].

The Nigerian government, through the National Control Programme (NMCP), together with several nongovernmental partners such as Roll Back Malaria (RBM) have made and are still making drastic efforts in reducing malaria transmission and associated child death through the implementation of (2009-2013) malaria control strategic plan and on the wide dissemination of malaria knowledge through mass distribution of long-lasting insecticide-impregnated nets (LLINs) within the selected state of the country. Their effort yielded a huge result within $2010-2015$ by reducing malaria prevalence from 52 to $45 \%$ [2]. The NMIS outcome between 2010-2015 indicated an improvement of about $5 \%$ in malaria prevalence reduction, though some regions are still lagging behind with tremendous malaria cases [2]. It has been and still being a leading cause of death among children between the age bracket ( 6 months -5 years) in Nigeria, mostly among the poor and rural communities $[1,2]$.

Recent research on malaria prevalence in other malaria endemic countries [8-14] and in Nigeria [5-7, 15-21] have identified major factors such as unavailability of LLINs, presence of other infections, illiteracy on the part of parents or caregiver, poverty, and inadequate dissemination of malaria knowledge, to be highly associated with the malaria disease transmissions.

Most of the studies in Nigeria have been largely limited to community and hospital based simple random sample survey among pregnant mothers [5, 17-19], however, very few studied clinical malaria cases among children $[15,20,22,23]$. Using data from 2010 Nigeria malaria indicator survey and the mapping malaria risk dataset in Africa (MARA), [5, 24] employed standard logistic regression and a Bayesian geostatistical modeling. Their results showed that environmental and climatic factors are major predictors of malaria parasite infection. Also, [25] used the 2008, Nigeria demographic health survey data (NDHS) to study the relationship between children's fever report and poverty in Nigeria. This study found that low fever occurrences were reported in the households that posses mosquito bed nets. However, no studies have been done on under-five malaria risk indicators in Nigeria using National level data.

The world is presently in the post MDG era and recently the WHO Global Technical Strategy for malaria 2016-2030 is endorsed with the objective of drastically reducing global malaria occurrences by at least $90 \%$, malaria related death by at least $90 \%$, eradicating malaria in at least 35 countries and preventing re-emergence of malaria in all the malaria free countries [26]. To meet the SDGs 2030 target on total malaria elimination and to also achieve Nigeria's own 2014-2020 agenda in reducing malaria-related deaths to zero level, investigation into individual and household (socio-economic, geographic, demographic and environmental) determinants of malaria prevalence and associated child mortality is paramount for the best strategic interventions. In other to achieve great success in re-strategizing policy measures, policy implementation that will extensively lower the malaria burden in the country, consistent investigation into the epidemiology and the major risk factors associated with malaria infection is paramount $[5,15,24]$.

In this paper, the 2015, Nigeria malaria indicator survey data (NMIS) was utilized to investigate the factors associated with malaria RDT status of children aged under 5 years in Nigeria and hence, this study contribute to highlight measures that may be implemented towards re-designing intervention strategies to achieve the SDGs 2016-2030 Agenda for total malaria elimination in Nigeria.

\section{Methods \\ The data}

The 2015 Nigeria Malaria Indicator Survey (NMIS) has been conducted by the National Population Commission (NPopC), the National Bureau of Statistics (NBS), the Malaria Elimination Program (NMEP) and the Malaria Partnerships in Nigeria, which was supported by PMSI-USAID, GFATM, DFID, UNICEF, WHO and the United Kingdom Department for International Development (DFID) and was carried out from October through December 2015 [2]. This was the second and more comprehensive malaria indicator survey implemented just one year after the first survey in 2010 and also after one year in the development of the new national malaria strategic plan that covers 2014-2020 [2]. This is an internationally recognized household survey, 
which is periodically conducted in high malaria endemic countries at the time of malaria season for the purpose of providing national level information on malaria indicators and prevalence. The NMIS captured a number of individual and household characteristics. A sample of 8148 households was selected from 333 clusters across the country, of which 138 clusters are in urban areas and about 195 clusters are from rural areas [2].

Children aged 6-59 months, who were born from women in the 8148 sampled households were tested for malaria and anaemia using blood samples. A total of 5236 children participated in the 2015 NMIS. Hence, children aged 6-59 months were used in this study.

\section{Response variable}

Malaria rapid diagnostic tests (RDTs) are immunochromatography form of tests which detect the presence of malaria antigens discharged from the parasitized red blood cells.

The World Health Organization (WHO) has supported the use of both microscopy and rapid diagnostic testing approach for malaria diagnosis. Microscopy being the oldest has been recognized as the standard approach for malaria diagnosis, but the application is however tedious. Microscopy requires an experienced (laboratory specialist) microscopist, relaxed environment, time, degree of operational expertise and cost [27]. In remote rural communities, microscopy may be subject to false negative results due to the fact that, malaria results are highly subject to human error attributed to loss of parasite during the staining procedure. Conversely RDTs does not require specialized equipments, long process and skilled personnel. The recent development in introduction of RDTs has been so fruitful towards early detection, prompt treatment and reduction of severe cases for effective 'test and treat-strategy recommended by WHO [28]. The RDT method has gained popularity in every situation and has been mostly applied during population based survey for immediate intervention, because it gives rapid result in a space of $15-30 \mathrm{~min}[29,30]$. Moreover, the systematic reviews have proven that the RDTs approach is a reliable diagnosis for malaria infection [31, 32].

Therefore, for the purpose of this study, the dependent variable is the binary response from the children RDT outcome where 1 signifies the presence of malaria infection and 0 for no malaria infection.

\section{Explanatory variables}

The explanatory variables were selected to give an answer to the study objective. The selected variables were based on previous studies to critically compare results. These include; i. Child's characteristics: sex of child (female, male); age of child (6-59 months; the anemic status of a child (yes, no); child treated fever before malaria test (yes, no).

ii. Geospatial: sampling enumeration clusters; region (North central, North East, North West, South East, South South, South West); type of place of residence (rural, urban).

iii. Mother's characteristics: mother's educational level (no education, primary, secondary and higher education)

iv. Head of household's characteristics: age of head of household (continuous), gender of head of household (female, male).

v. Socio-economic characteristics of the household: wealth index (poorer, middle-range, richer, richest); number of household members (continuous); availability of some critical household possessions such as radio (yes, no); television (yes, no); electricity (yes, no); household wall material (mud-wood-others), roof (thatched-wood-others, zinc-metal-roof), main floor (cement-wood-other, palm-sand-others); source of drinking water (protected water, tappiped water, unprotected water).

vi. Environmental and sanitation characteristics: Use of mosquito indoor residual spray (yes, no); use of mosquito net (yes, no); total number of nets used (continuous); toilet facility (flush toilet, no toilet, pit-latrine); distance from water source $(<30 \mathrm{~min}$, 31-49 min, 50-90 min, > $90 \mathrm{~min}$, on premises).

\section{Statistical methods}

Under complex survey design with unequal weighting, the ordinary logistic regression statistical estimates will be inappropriate for the analysis [33-36]. Accordingly, this study employed the mixed effects logistic regression model approach under the generalized linear mixed models (GLMMs) framework which accounts for the complexity of the sampling design. Moreover, the GLMM accommodates both random and fixed effects in the model [37-39].

Let $y_{i k t}$ be the binary response variable of the $i$ th child in the $k$ th household within the $t$ th sampling clusters. Let $\pi_{i k t}=P\left(y_{i k t}=1\right)$ denote the probability that an $i$ th child RDT outcome in the $k$ th household, within the $t$ th cluster is positive. Suppose $\mathbf{x}_{i k t}^{\prime}$ is the row vector of covariates, which corresponds to the $i$ th child in the $k$ th household and the $t$ th cluster and $\beta$ is the vector of unknown model parameters. Then, following [14, 40-42], the generalized linear mixed models (GLMMs) framework of the mixed effect logistic regression models formulates the logit of 
$\pi_{i k t}$ as a function of the covariates $\mathbf{x}_{i k t}^{\prime}$ and the random cluster effect $\gamma_{t}$, as:

$$
\operatorname{logit}\left(\pi_{i k t}\right)=\log \left[\frac{\pi_{i k t}}{1-\pi_{i k t}}\right]=\mathbf{x}_{i k t}^{\prime} \beta+\gamma_{t} .
$$

\section{Results}

Weighted mixed effects logistic regression model was regressed on the explanatory variables. The weights were the sampling weights which were used in the NMIS complex survey design. To avert the influence of confounding variables, all the main effects were retained in the model. It was assessed as to whether any interaction terms were needed to be incorporated into the model. This was examined by fitting each of the two-way interaction terms formed from all the explanatory variables, one at a time to the model that had all the main effects. Interactions which highly improved the goodness of fit and highly significant $(\mathrm{P}<0.10)$ were sequentially added to the model until there was no significant interaction effect to be included in the model.

Accordingly, only four interaction effects, namely region and type of place of residence, wealth index and type of place of residence, age and gender of the head of household, and age of head of the household and the number of household members. Consequently, the final model included all the main effects and the four two-way interaction effects.

All the model fits and estimates were obtained using the SAS GLIMMIX procedure [43]. The model fit was assessed using the ratio of the generalized chi-square statistics and it's degree of freedom, which yielded 0.90 . This result indicated a good model fit with no residual overdispersion. The random effect cluster, which accounted for the complexity of the sampling design is significant as shown in Table 1. The result shows that there is heterogeneity between clusters. The cluster variability accounts about $50 \%$ the total variability of under-five child RDT outcome.

The type III tests for the fixed effects in Table 2 shows that region, mother's level of education, child's anaemia level, age of the child, age of head of household, toilet facility, number of household members, cluster altitude in meters, availability of electricity, type of place of residence (urban or rural) and child's fever report two weeks prior to survey and the interactions between

Table 1 Covariance parameter estimates

\begin{tabular}{lllcl}
\hline Cov. parameter & Estimate & Standard error & Z value & P-value \\
\hline Clusters & 0.8853 & 0.1142 & 7.76 & $<0.0001$ \\
Residual & 0.9022 & 0.0183 & 49.42 & $<0.0001$ \\
\hline
\end{tabular}

Table 2 Type III tests for fixed effects

\begin{tabular}{|c|c|c|c|c|}
\hline Effects & Num DF & Den DF & F value & P-value \\
\hline Region & 5 & 314 & 6.70 & $<0.0001$ \\
\hline Mother's education & 3 & 494 & 4.97 & 0.0021 \\
\hline Child's age & 4 & 1151 & 53.14 & $<0.0001$ \\
\hline Child's anaemia status & 1 & 305 & 185.47 & $<0.0001$ \\
\hline Age of household head & 1 & 4868 & 4.59 & 0.0322 \\
\hline Toilet facility & 2 & 285 & 12.40 & $<0.0001$ \\
\hline $\begin{array}{l}\text { Number of household mem- } \\
\text { bers }\end{array}$ & 1 & 4868 & 8.04 & 0.0046 \\
\hline Cluster altitude in metres & 1 & 71 & 0.63 & $<0.0001$ \\
\hline Availability of electricity & 1 & 61 & 0.79 & 0.0457 \\
\hline Sex of a child & 1 & 320 & 1.26 & 0.2627 \\
\hline Prior child's fever status & 1 & 4868 & 89.96 & $<0.0001$ \\
\hline Distance from water source & 3 & 354 & 0.19 & 0.9000 \\
\hline Mosquito indoor spray & 1 & 30 & 0.12 & 0.7292 \\
\hline Number of mosquito nets used & 1 & 4868 & 0.28 & 0.5967 \\
\hline Child slept under bed net & 1 & 285 & 0.18 & 0.6683 \\
\hline Number of rooms & 1 & 4868 & 0.22 & 0.6423 \\
\hline Household's main floor & 2 & 331 & 1.84 & 0.1610 \\
\hline Households's main wall & 2 & 228 & 1.44 & 0.2395 \\
\hline Household's main roof & 2 & 230 & 6.40 & 0.0012 \\
\hline Households's wealth index & 4 & 466 & 1.74 & 0.1430 \\
\hline Availability of television & 1 & 190 & 0.05 & 0.8302 \\
\hline Gender of head of household & 1 & 148 & 0.67 & 0.4132 \\
\hline Place of residence & 1 & 314 & 13.55 & 0.0003 \\
\hline Source of drinking water & 2 & 255 & 1.87 & 0.1555 \\
\hline $\begin{array}{l}\text { Number of household } \\
\text { members* age of head of } \\
\text { household }\end{array}$ & 1 & 4868 & 5.09 & 0.0241 \\
\hline $\begin{array}{l}\text { Gender * age of head of } \\
\text { household }\end{array}$ & 1 & 4868 & 2.76 & 0.0967 \\
\hline $\begin{array}{l}\text { Wealth index * type of resi- } \\
\text { dence }\end{array}$ & 4 & 466 & 2.49 & 0.0424 \\
\hline $\begin{array}{l}\text { Region * type of place of } \\
\text { residence }\end{array}$ & 5 & 314 & 1.95 & 0.0862 \\
\hline
\end{tabular}

number of household members and age of head of household, gender and age of head of household, region and type of place of residence significantly associated child's malaria RDT outcome.

In this study, the results of the main effect parameter estimates, the odds ratios (OR), the 95\% confidence intervals and the P-values are shown in Table 3. Highlighted also were some of the results from Table 3.

The age effect shows that as a child gets older, the odd of malaria RDT positive outcome. The risk of anaemia was found to be associated with malaria status of under-five children. The odds of positive RDT outcome for under-five anaemic children is 3.16 times more than that of the non-anaemic, but otherwise identical children. 
Table 3 Parameter estimates of odds ratio for the main effects

\begin{tabular}{|c|c|c|c|c|c|c|}
\hline \multirow[t]{2}{*}{ Effect } & \multirow[t]{2}{*}{ Estimates } & \multirow[t]{2}{*}{ Standard error } & \multirow[t]{2}{*}{ Odd ratio } & \multicolumn{2}{|l|}{$95 \% \mathrm{Cl}$} & \multirow[t]{2}{*}{ P-value } \\
\hline & & & & Lower & Upper & \\
\hline Intercept & -4.8896 & 0.5943 & 0.0075 & 0.0023 & 0.0241 & $<0.0001$ \\
\hline \multicolumn{7}{|l|}{ Region (Ref. North West) } \\
\hline South East & 0.1086 & 0.3779 & 1.1147 & 0.5315 & 2.3380 & 0.7741 \\
\hline South South & -0.5394 & 0.4571 & 0.5831 & 0.2380 & 1.4283 & 0.2389 \\
\hline South West & 0.3979 & 0.3578 & 1.4887 & 0.7383 & 3.0017 & 0.2670 \\
\hline North Central & -0.3953 & 0.4453 & 0.6735 & 0.2814 & 1.6120 & 0.3753 \\
\hline North East & -1.1844 & 0.4844 & 0.3059 & 0.1184 & 0.7906 & 0.0150 \\
\hline \multicolumn{7}{|l|}{ Place of residence (Ref. urban) } \\
\hline Rural & 1.5215 & 0.4590 & 4.5791 & 1.8624 & 11.2587 & 0.0010 \\
\hline \multicolumn{7}{|l|}{ Household wealth index (Ref. richest) } \\
\hline Poorest & 1.2669 & 0.4368 & 3.5498 & 1.5080 & 8.3564 & 0.00391 \\
\hline Poorer & 1.7230 & 0.3731 & 5.6013 & 2.6959 & 11.6380 & $<0.0001$ \\
\hline Middle-range & 0.8989 & 0.2645 & 2.4569 & 1.4630 & 4.1260 & 0.0007 \\
\hline Richer & 0.6020 & 0.1953 & 1.8258 & 1.2451 & 2.6772 & 0.0022 \\
\hline \multicolumn{7}{|l|}{ Mother's educational level (Ref. more than secondary) } \\
\hline No education & 0.7156 & 0.2077 & 2.0454 & 1.3614 & 3.0731 & 0.0006 \\
\hline Primary & 0.4260 & 0.2034 & 1.5311 & 1.0277 & 2.2811 & 0.0368 \\
\hline Secondary & 0.4363 & 0.1868 & 1.5470 & 1.0727 & 2.2310 & 0.0199 \\
\hline \multicolumn{7}{|l|}{ Anti-malaria spraying (Ref. yes) } \\
\hline No & -0.1229 & 0.3516 & 0.8844 & 0.5020 & 1.7616 & 0.7292 \\
\hline \multicolumn{7}{|l|}{ Use of mosquito nets (Ref. yes) } \\
\hline No & -0.0348 & 0.0811 & 0.9658 & 0.8238 & 1.1323 & 0.6683 \\
\hline \multicolumn{7}{|l|}{ Child's age in months (Ref. age 6-12 months), months } \\
\hline Age 13-24 & 0.5329 & 0.1220 & 1.7039 & 1.3415 & 2.1641 & $<0.0001$ \\
\hline Age $25-36$ & 0.9648 & 0.1224 & 2.6243 & 2.0645 & 3.3358 & $<0.0001$ \\
\hline Age 37-48 & 1.2785 & 0.1218 & 3.5912 & 2.8286 & 4.5596 & $<0.0001$ \\
\hline Age 49-59 & 1.6047 & 0.1259 & 4.9764 & 3.8882 & 6.3883 & $<0.0001$ \\
\hline \multicolumn{7}{|l|}{ Child's gender (Ref. male) } \\
\hline Female & -0.0756 & 0.0673 & 0.9272 & 0.8126 & 1.0544 & 0.2627 \\
\hline \multicolumn{7}{|l|}{ Child's anaemic status (Ref. not anaemic) } \\
\hline Anemic & 1.0928 & 0.0802 & 2.9826 & 2.5486 & 3.4906 & $<0.0001$ \\
\hline \multicolumn{7}{|l|}{ Prior child's fever status (Ref. no fever) } \\
\hline Child had fever & 0.6767 & 0.0714 & 1.9674 & 1.7106 & 2.2627 & $<0.0001$ \\
\hline Age of head of household (continuous) & 0.0189 & 0.0059 & 1.0191 & 1.0074 & 1.0309 & 0.0013 \\
\hline Number of household members (continuous) & 0.0961 & 0.0339 & 1.1008 & 1.0301 & 1.1762 & 0.0046 \\
\hline Number of net used & -0.0141 & 0.0266 & 0.9860 & 0.9359 & 1.0388 & 0.5967 \\
\hline Number of rooms (continuous) & -0.0119 & 0.0257 & 0.9881 & 0.9396 & 1.0643 & 0.6423 \\
\hline Cluster altitude in metres (continuous) & 0.0003 & 0.0023 & 1.0003 & 0.9910 & 1.1003 & $<0.0001$ \\
\hline \multicolumn{7}{|l|}{ Availability of electricity (Ref. yes) } \\
\hline No & 0.1372 & 0.1306 & 1.1471 & 0.8880 & 1.4817 & 0.0457 \\
\hline \multicolumn{7}{|l|}{ Availability of television (Ref. yes) } \\
\hline No & 0.0261 & 0.1216 & 1.0265 & 0.8088 & 1.3027 & 0.8302 \\
\hline \multicolumn{7}{|l|}{ Type of toilet facility (Ref. flush toilet) } \\
\hline No toilet facility & 0.4919 & 0.1540 & 1.6354 & 1.2093 & 2.2117 & 0.0016 \\
\hline Pit latrine & -0.0582 & 0.1387 & 0.9434 & 0.7189 & 1.2382 & 0.6749 \\
\hline \multicolumn{7}{|c|}{ Distance from water source to the household (Ref. $>90 \mathrm{~min}$ ), min } \\
\hline$<30$ & -0.0338 & 0.0857 & 0.9668 & 0.8174 & 1.1437 & 0.6937 \\
\hline $31-49$ & -0.0006 & 0.2413 & 0.9995 & 0.6228 & 1.6038 & 0.9982 \\
\hline
\end{tabular}


Table 3 (continued)

\begin{tabular}{|c|c|c|c|c|c|c|}
\hline \multirow[t]{2}{*}{ Effect } & \multirow[t]{2}{*}{ Estimates } & \multirow[t]{2}{*}{ Standard error } & \multirow[t]{2}{*}{ Odd ratio } & \multicolumn{2}{|l|}{$95 \% \mathrm{Cl}$} & \multirow[t]{2}{*}{ P-value } \\
\hline & & & & Lower & Upper & \\
\hline $50-90$ & 0.1116 & 0.2148 & 1.1181 & 0.7339 & 1.7034 & 0.6036 \\
\hline \multicolumn{7}{|c|}{ Household main roof (Ref. zinc/metal) } \\
\hline Wood material & -0.1845 & 0.1285 & 0.8315 & 0.6464 & 1.0697 & 0.1524 \\
\hline Thatched/palm leaf & -0.3325 & 0.1273 & 0.7171 & 0.5588 & 0.9204 & 0.0096 \\
\hline \multicolumn{7}{|c|}{ Household main floor (Ref. wood material) } \\
\hline Cement & 0.0443 & 0.1387 & 1.0453 & 0.7965 & 1.3718 & 0.7497 \\
\hline Localdung plaster/earth & 0.2404 & 0.1594 & 1.2718 & 0.9305 & 1.7382 & 0.1326 \\
\hline \multicolumn{7}{|c|}{ Household main wall (Ref. mud/bamboo/wood) } \\
\hline Cement block & 0.0894 & 0.1146 & 1.0936 & 0.8736 & 1.3690 & 0.4361 \\
\hline No walls & -0.2099 & 0.1568 & 0.8107 & 0.5962 & 1.1023 & 0.1821 \\
\hline \multicolumn{7}{|c|}{ Type of drinking water (Ref. unprotected water) } \\
\hline Protected water & -0.1229 & 0.1626 & 0.8844 & 0.6430 & 1.2163 & 0.4505 \\
\hline Tap/pipped water & -0.1962 & 0.1017 & 0.8218 & 0.6733 & 1.0031 & 0.0549 \\
\hline
\end{tabular}

Table 4 Parameter estimates of odds ratio for the interaction effects

\begin{tabular}{|c|c|c|c|c|c|c|}
\hline \multirow[t]{2}{*}{ Parameter } & \multirow[t]{2}{*}{ Estimates } & \multirow[t]{2}{*}{ Standard error } & \multirow[t]{2}{*}{ Odd ratio } & \multicolumn{2}{|l|}{$95 \% \mathrm{Cl}$} & \multirow[t]{2}{*}{ P-value } \\
\hline & & & & Lower & Upper & \\
\hline \multicolumn{7}{|c|}{ Wealth index * type of place of residence (Ref. richest and urban) } \\
\hline Poorest ${ }^{*}$ rural & -1.0308 & 0.5076 & 0.3567 & 0.1319 & 0.9647 & 0.0429 \\
\hline Poorer * rural & -1.2839 & 0.4490 & 0.2770 & 0.1149 & 0.6677 & 0.0044 \\
\hline Middle-range * rural & -0.8036 & 0.3632 & 0.4477 & 0.2197 & 0.9124 & 0.0274 \\
\hline Richer * rural & -0.8738 & 0.3237 & 0.4174 & 0.2213 & 0.7871 & 0.0072 \\
\hline $\begin{array}{l}\text { Number of household members * } \\
\text { age of household head }\end{array}$ & -0.0015 & 0.0007 & 0.9984 & 0.9972 & 0.9998 & 0.0241 \\
\hline \multicolumn{7}{|l|}{ Gender * age of head of household } \\
\hline Female & -0.0122 & 0.0073 & 0.9879 & 0.9738 & 1.0022 & 0.0967 \\
\hline \multicolumn{7}{|c|}{ Region * type of place of residence (Ref. North West and urban) } \\
\hline South East * rural & -0.9842 & 0.5224 & 0.3737 & 0.1342 & 1.0405 & 0.0605 \\
\hline South South * rural & -0.35805 & 0.5361 & 0.6991 & 0.2444 & 1.9992 & 0.5048 \\
\hline South West * rural & 0.2646 & 0.5000 & 1.3028 & 0.4889 & 3.4712 & 0.5972 \\
\hline North Central * rural & 0.1137 & 0.5056 & 1.1204 & 0.4159 & 3.0182 & 0.8222 \\
\hline North East * rural & 0.7067 & 0.5449 & 2.0273 & 0.6968 & 5.8985 & 0.1956 \\
\hline
\end{tabular}

The mother's educational level was significantly associated with the risk of malaria. The positive outcome of the malaria RDT increased with a decreasing level of the mother's education. A child who has an illiterate mother is 2.0454 ( $P$-value $=0.0006)$ more likely to have malaria positive RDT outcome otherwise identical mother with a higher educational level.

The interaction effects estimate summary is given in Table 4. The interaction effects between regions (South East, South South, South West, North Central, North East and North West) and type of place of residence (urban or rural) is presented in Fig. 1. Figure 1 shows that malaria prevalence is higher in rural areas than that of the urban areas in all the regions of Nigeria.

Figure 2 presents the interaction effect involving type of place of residence and wealth index (socio-economic status) of households. The prevalence of malaria was significantly very high among poorer and poorest in both urban and rural households compared to (middlerange, richer and richest) households.

The interaction between gender and age of head of household is presented in Fig. 3. The figure shows that increase in ages of both male and female head of 

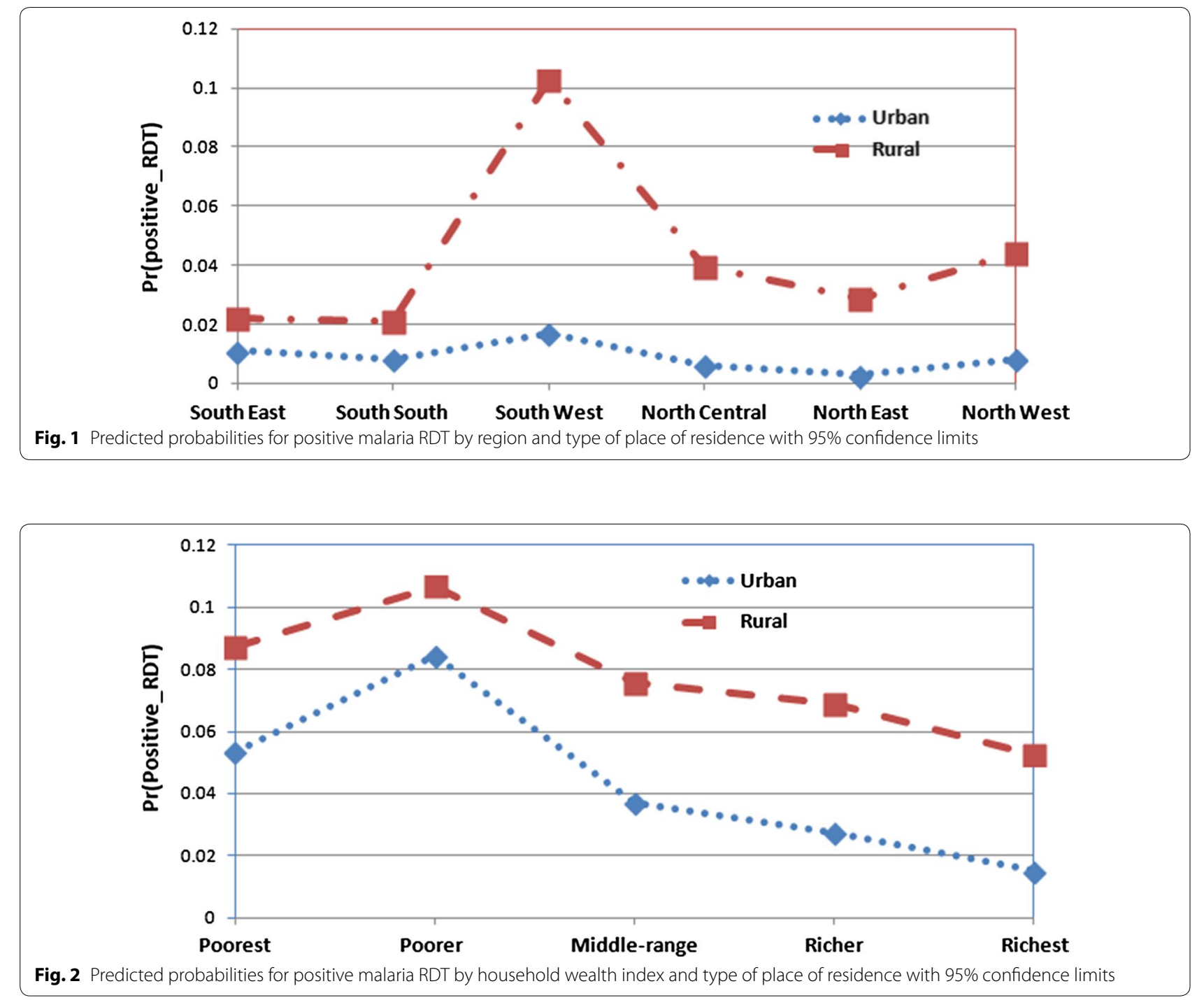

household increases the odd of malaria prevalence on the under-five children.

Finally Fig. 4 presents the interaction effect between the ages of head of household and household size. In Fig. 4, it shows that the number of household members increases as the age of head of household increases which also impact heavily on the malaria RDT outcome of children under- 5 years in Nigeria.

\section{Discussion}

Understanding the critical risk factors and prevalence of malaria among children in a household is very informative and crucially important in re-designing appropriate intervention strategies for final malaria eradication in Nigeria. This study is aimed to investigate the determinant of malaria infection among Nigerian children aged under 5 years using the 2015 NMIS data.

The use of mosquito bed net, has insignificant effect on the under-five child's malaria RDT outcome. This result is in line with the findings of $[9,14,44]$. But this is contrary to the results obtained from studies in Ethiopia [8], Burkina-Faso [13] and Rwanda [45], they observed significant relationship between those predictor variables and malaria prevalence among children under 5 years. The Roll Back Malaria Partners, the WHO and many other private donors have contributed tremendously in mosquito bed net distribution in many regions in Nigeria, which might contribute to the reason for the insignificant effect of mosquito bed net on under-five children RDT outcome. 


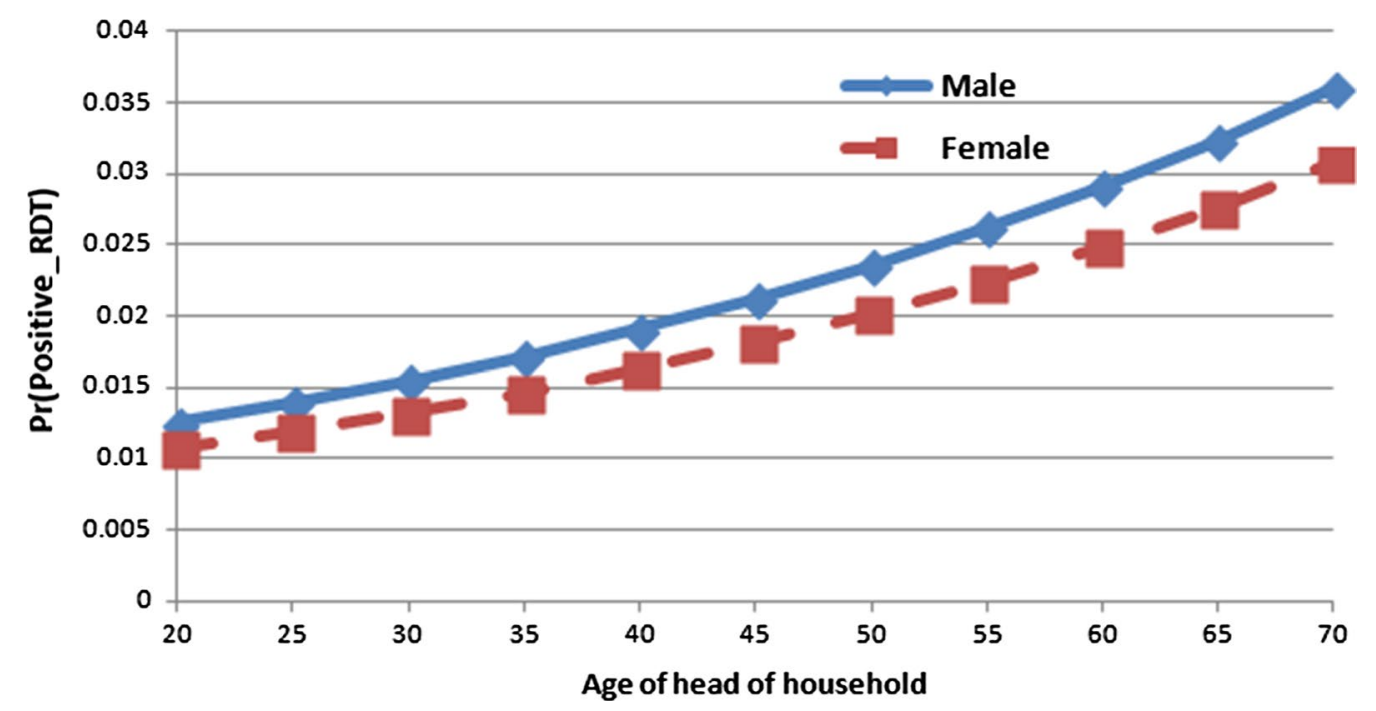

Fig. 3 Predicted probabilities for positive malaria RDT by gender and age of head of household with 95\% confidence limits

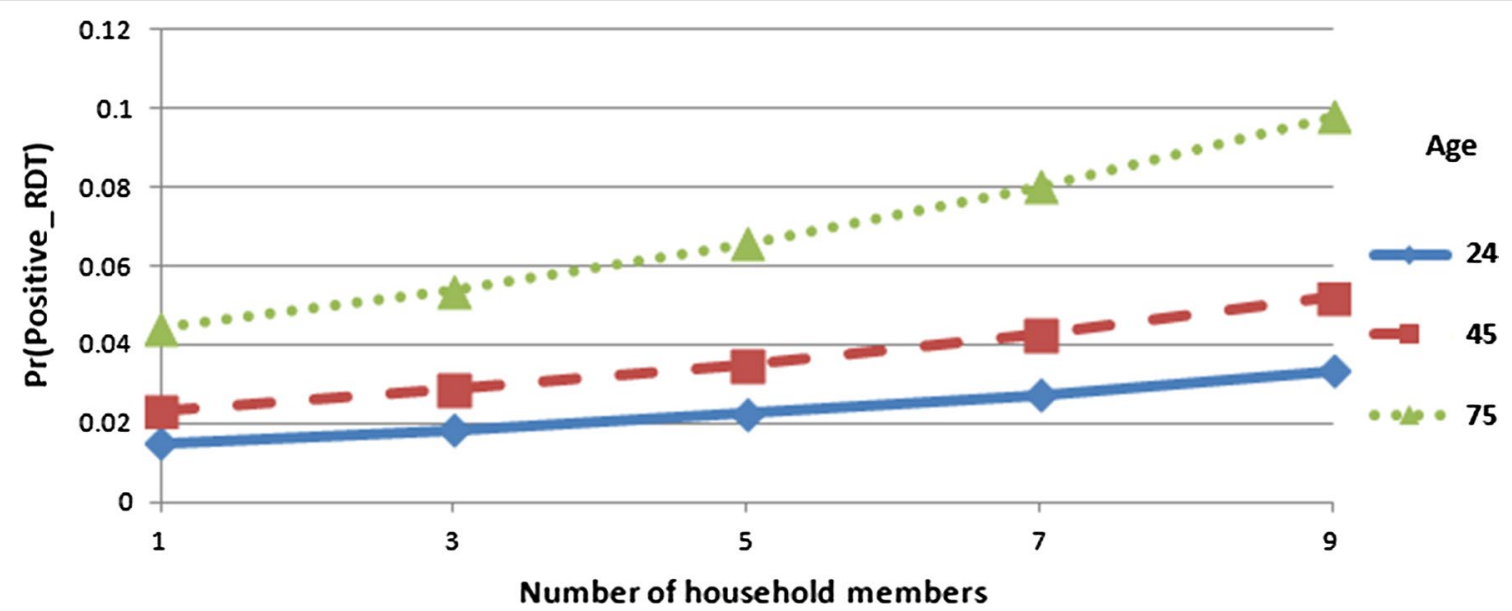

Fig. 4 Predicted probabilities for positive malaria RDT by age of head of household and number of household members with $95 \%$ confidence limits

In this study, it was observed that as a child gets older, the odd of malaria infection increases. Children between the ages of 6-24 months are found to be less affected by the malaria parasite than older children between ages 49-59 months. This result is consistent with recent results found by many studies on under- 5 year children. From the findings, it was observed that a child's vulnerability to malaria infection increases with increase in age, older children being more at the risk of malaria infection $[9,14]$. This was evident from recent studies on underfive children that malaria positivity increasing with age $[4,8,12,16,17]$. A child between age 0 and 13 months might still be protected by the maternal antibodies, mothers give more attention to children under one year and as the child gets older outdoor activities exposes them to more malaria risk $[9,15,16]$. Similarly, the results has shown that a child's gender has no association with malaria infection, which is similar to the results obtained by $[8,13,14]$.

This study has observed a similar result with [25] that, malaria RDT status of the under-five children in Nigeria was positively associated with anaemia risk. This means that for the anaemic children, the RDT outcome tends to be positive and may require further investigation to ascertain if the result might be a case of RDT sensitivity issues. 
Maternal education plays a very important role in the child's health in a household. The result of this study shows a significant association between educational level of the child's mother and malaria prevalence. This finding is similar to the studies carried out by [10, 14]. It is believed that since mothers are at the centre of family well being, their exposure through education is paramount to understanding health related issues and preventive measures for malaria infections towards their children.

Regarding geographical impact on malaria prevalence, the finding shows a significant geographical variation in malaria prevalence among Nigerian children. Children living in the North West, North Central, North East, and South West were highly associated with high malaria risk compared to those residing in the South East and South West regions. This result is consistent with similar results found from published studies $[4,24]$.

\section{Conclusion}

In this paper, a GLMM was fitted and the complexity of the designs were incorporated in the model. The heterogeneity among clusters is found to be significant and the effects were accounted in the analysis of the factors effect.

The level of under-development in Nigeria presents a serious challenge for malaria eradication. The findings from this study have also provided insight into socioeconomic and mother's educational level. Mother's educational level has been found to influence her children's vulnerability to malaria infection. Having better educated mothers is a human capital for the nation and the family at large. Therefore, child malaria eradication and information strategy should incorporate mother's education enhancement.

Investigation into the significant association between under-five children RDT outcome and their anaemic test will be one of the alarming results about RDT diagnostic method. This is perhaps that anaemic children RDT outcome tends to show positive outcome or vice-versa. Therefore, one of the future direction of this research is to investigate the joint distribution of anaemia test status and the RDT outcome on under-five children.

\section{Abbreviations}

OR: Odds ratios; EAs: Enumeration area; PSU: Primary sampling unit; GLMMs: Generalized linear mixed models; RDT: Rapid diagnostic test; WHO: World Health Organization; MDGs: Millennium Development Goals; SDGs: Sustainable Development Goals; DFID: Department for International development; NPopC: National Population Commission; NPHC: National Population and housing Census; UNICEF: The United Children's Emergency Fund; USAID: The United States Agency for International Development; GFATM: Global Fund to Fight AIDS, Tuberculosis and Malaria; NMEP: National Malaria Eradication Program.
}

\section{Authors' contributions}

CLJU and TTZ conceptualized the modeling idea; CLJU performed the analysis; both CLJU and TTZ jointly drafted and revised the manuscript. All authors read and approved the final manuscript.

\section{Acknowledgements}

The authors appreciate the Measure DHS, Calverton Macro, USA, National Bureau of Statistics, National Malaria Control programme of the Federal Ministry of Health, Abuja and other contributor for granting the Authors access to the 2015 NMIS data. The first author also appreciates the study leave and the opportunity granted by the University of Nigeria Nsukka, Nigeria.

\section{Competing interests}

The authors declare that they have no competing interests.

\section{Availability of data and materials}

The data set for this study was obtained by request from Measure Demographic Health Survey (DHS) website: http://www.dhsprogram.com/data.

\section{Ethics approval and consent to participate}

The ethical clearance for the survey was obtained from measure DHS and the ethical committee of ICF Macro (Calverton, MD, USA).

\section{Funding}

None.

\section{Publisher's Note}

Springer Nature remains neutral with regard to jurisdictional claims in published maps and institutional affiliations.

Received: 13 June 2018 Accepted: 29 November 2018

Published online: 05 December 2018

\section{References}

1. WHO. World malaria report. Geneva: World Health Organization; 2017.

2. Programme NMC. Nigeria MIS final report. Abuja: Federal Republic of Nigeria; 2015.

3. WHO and UN Partners. Country statistics and global health estimates. Abuja: WHO Statistics Profile; 2015.

4. Adigun AB, Gajere EN, Oresanya O, Vounatsou P. Malaria risk in Nigeria: Bayesian geostatistical modelling of 2010 malaria indicator survey data. Malar J. 2015;14:156.

5. Gunn JKL, Ehiri JE, Jacobs ET, Ernst KC, Pettygrove S, Kohler LN. Population-based prevalence of malaria among pregnant women in Enugu State, Nigeria: the Healthy Beginning Initiative. Malar J. 2015;14:438.

6. Onwujekwe O, Uguru N, Etiaba E, Chikezie I, Uzochukwu B, Adjagba A. The economic burden of malaria on households and the health system in Enugu State Southeast Nigeria. PloS ONE. 2013;8:e78362.

7. Oladepo O, Tona GO, Oshiname FO, Titiloye MA. Malaria knowledge and agricultural practices that promote mosquito breeding in two rural farming communities in Oyo State, Nigeria. Malar J. 2010;9:91.

8. Ayele D, Zewotir T, Mwambi H. Prevalence and risk factors of malaria in Ethiopia. Malar J. 2012;11:195.

9. Gahutu JB, Steininger C, Shyirambere C, Zeile I, Cwinya-Ay N, Danquah I, et al. Prevalence and risk factors of malaria among children in southern highland Rwanda. Malar J. 2011;10:134.

10. Sultana M, Sheikh N, Mahumud RA, Jahir T, Islam Z, Sarker AR. Prevalence and associated determinants of malaria parasites among Kenyan children. Trop Med Int Health. 2017;45:25.

11. Lowe R, Chirombo J, Tompkins AM. Relative importance of climatic, geographic and socio-economic determinants of malaria in Malawi. Malar J. 2013;12:416.

12. Clark TD, Greenhouse B, Njama-Meya D, Nzarubara B, Maiteki-Sebuguzi C, Staedke SG. Factors determining the heterogeneity of malaria incidence in children in Kampala, Uganda. J Infect Dis. 2008;198:393-400. 
13. Baragetti M, Fournet F, Henry M, Assi S, Ouedraogo H, Rogier C. Social and environmental malaria risk factors in urban areas of Ouaga-dougou, Burkina Faso. Malar J. 2009:8:13.

14. Roberts $D$, Matthews $G$. Risk factors of malaria in children under the age of five years old in Uganda. Malar J. 2016;15:246.

15. Uzochukwu BSC, Onwujekwe EO, Onoka CA, Ughasoro MD. Rural-urban differences in maternal responses to childhood fever in South East Nigeria. PloS ONE. 2008;3:e1788.

16. Dawaki S, Al-Mekhlafi HM, Ithoi I, Ibrahim J, Atroosh WM, Abdulsalam AM, et al. Is Nigeria winning the battle against malaria? Prevalence, risk factors and KAP assessment among Hausa communities in Kano State. Malar J. 2016;15:351.

17. Dogara MM, Ocheje AJ. Prevalence of malaria and risk factors among patients attending Dutse General Hospital, Jigawa State, Nigeria. Int J Pub Environ Health. 2016;11:270-7.

18. Agomo CO, Oyibo WA. Factors associated with risk of malaria infection among pregnant women in Lagos, Nigeria. Infect Dis Poverty. 2013;2:19.

19. Fana SA, Bunza MDA, Anka SA, Imam AU, Nataala SU. Prevalence and risk factors associated with malaria infection among pregnant women in a semi-urban community of north-western Nigeria. Inf Dis Poverty. 2015;4:24.

20. Olasehinde GI, Ajay AA, Taiwo SO, Adekeye BT, Adeyeba OA. Prevalence and management of falciparum malaria among infants and children in Ota, Ogun State, Southwestern Nigeria. Afr J Clin Exper Microbiol. 2010;11:159-63.

21. Okonko IO, Soleye FA, Amusan TA, Ogun AA, Udeze AO, Nkang AO. Prevalence of malaria plasmodium in Abeokuta, Nigeria. Malays J Microbiol. 2009;5:113-8.

22. Nwaorgu OC, Orajaka BN. Prevalence of malaria among children 1-10 years old in communities in Awka North Local Government Area, Anambra State South East Nigeria. Ethiopia Int J Multidiscip Res. 2011;5:264-81.

23. Ejezie GC, Ezedinachi ENU, Usanga EA, Gemade Ell, Ikpatt NW, Alaribe AAA. Malaria and its treatment in rural villages of Aboh Mbaise, Imo State, Nigeria. Acta Trop. 1990;48:17-24.

24. Onyiri N. Estimating malaria burden in Nigeria: a geostatistical modelling approach. Geospat Health. 2015;10:306.

25. Yusuf OB, Adeoye BW, Oladepo OO, Peters DH, Bishai D. Poverty and fever vulnerability in Nigeria: a multilevel analysis. Malar J. 2010;9:235.

26. WHO. Global technical strategy for malaria 2016-2030. Geneva: World Health Organization; 2015

27. Maltha J, Gillet $P$, Jacobs J. Malaria rapid diagnostic tests in endemic settings. Clin Microbiol Inf. 2013:19:399-407.

28. WHO. Guildelines for the treatment of malaria. 2nd ed. Geneva: World Health Organization; 2010

29. WHO. Malaria rapid diagnostic test performance: summary results of WHO product testing of malaria RDTs: round 1-7 (2008-2016). Geneva: World Health Organization; 2017.
30. Wongsrichnalai C, Barcus MJ, Muth S, Sutamihardja A, Wernsdorfer WH. A review of malaria diagnostic tools: microscopy and rapid diagnostic test (RDT). Am J Trop Med Hyg. 2007;6:119-27.

31. Abba K, Deeks JJ, Olliaro PL, Naing C, Jackson SM, Takwoingi Y, et al. Rapid diagnostic tests for diagnosing uncomplicated $P$. falciparum malaria in endemic countries. Cochrane Database Syst Rev. 2011;7:CD008122.

32. Boyce MR, Menya D, Turner EL, Laktabai J, Prudhomme O'MW. Evaluation of malaria rapid diagnostic test (RDT) use by community health workers: a longitudinal study in western Kenya. Malar J. 2018;17:2016.

33. Heeringa SG, West BT, Berglund PA. Applied survey data analysis. 2nd ed. New York: Chapman \& Hall/CRC; 2017.

34. Rao JNK, Scott AJ. The analysis of categorical data from complex sample surveys: Chi-squared tests for goodness of fit and independence in twoway tables. J Am Stat Assoc. 1998;76:221-30.

35. Wilson JR, Koehler KJ. Hierarchical models for cross-classified overdispersed multinomial data. J Bus Econ Stat. 1991;9:103-10.

36. Rozi S, Mahmud S, Lancaster G, Hadden W, Pappas G. Multilevel modeling of binary outcomes with three-level complex health survey data. Open J Epidemiol. 2017;7:27

37. McCullagh P, Nelder JA. Generalized linear models. 2nd ed. New York: Chapman \& Hall; 1989.

38. Breslow NE, Clayton DG. Approximate inference in generalized linear mixed models. J Am Stat Assoc. 1993;88:9-25.

39. Neuhaus JM, Kalbfleisch JD, Hauck WW. A comparison of cluster-specific and population-averaged approaches for analyzing correlated binary data. Int Stat Rev. 1991;59:25-35.

40. Pendergast JF, Gange SJ, Newton MA, Lindstrom MJ, Palta M, Fisher MR. A survey of methods for analyzing clustered binary response data. Int Stat Rev. 1996:89:118.

41. Capanu M, Gönen M, Begg CB. An assessment of estimation methods for generalized linear mixed models with binary outcomes. Stat Med. 2013;32:4550-66

42. Agresti A. An introduction to categorical data analysis. 2nd ed. New Jersey: Wiley; 1996

43. SAS. PHREG and Procedures, REGRESSION. SAS/STAT 9.4 User's Guide. Cary: SAS Institute Inc; 2017.

44. Okebe J, Mwesigwa J, Kama EL, Ceesy SJ, Njie F. A comparative case control study of the determination of the clinical malaria in the Gambia. Malar J. 2014;13:306.

45. Kateera F, Mens PF, Hakizimana E, Ingabire CM, Muragijemariya L, Karinda $P$, Grobusch MP. Malaria parasite carriage and risk determinants in a rural population: a malariometric survey in Rwanda. Malar J. 2015;14:16.
Ready to submit your research? Choose BMC and benefit from:

- fast, convenient online submission

- thorough peer review by experienced researchers in your field

- rapid publication on acceptance

- support for research data, including large and complex data types

- gold Open Access which fosters wider collaboration and increased citations

- maximum visibility for your research: over $100 \mathrm{M}$ website views per year

At BMC, research is always in progress.

Learn more biomedcentral.com/submissions 